\title{
Self-correction among Iranian EFL Learners: An Investigation into their Preferences for Corrective Feedback
}

\author{
Reza Pishghadam \\ Ferdowsi University of Mashhad, Iran \\ Email: pishghadam@um.ac.ir \\ Mohammad Reza Hashemi \\ Ferdowsi University of Mashhad, Iran \\ Email: hashemi@um.ac.ir \\ Paria Norouz Kermanshahi \\ Ferdowsi University of Mashhad, Iran \\ Email: paria.pk@stu-mail.um.ac.ir
}

\begin{abstract}
This article reports on the self-correction of Iranian EFL learners, their preferences regarding corrective feedback and the speech act through which they correct their own mistakes. The participants were 160 EFL learners from different language institutes, who have been selected from females and males, adults and teenagers and three different proficiency levels- starter, intermediate and advanced. A questionnaire was designed which proposed a situation where a mistake is made. Based on the frequency and percentage of the options selected by the participants, the provided answers were analyzed and the influence of age, gender and proficiency level on the speech act of correction was discussed in detail. The obtained results suggested that Iranian EFL learners prefer self-correction to teacher and peer correction when they themselves notice a mistake in their utterances.
\end{abstract}

Index Terms - self-correction, speech act, corrective feedback

\section{INTRODUCTION}

In most foreign language classrooms, the sociocultural context of the language is taken for granted. However, we must keep in mind that to achieve the communicative goal in ELT classrooms, not only the sociolinguistic ability of the learners but also their sociocultural knowledge must be given heed to by EFL/ ESL teachers. A major field which can help in this regard is that of 'speech acts'. Since learners need to use speech acts in all daily interactions, they must be taught how to produce, interpret and comprehend them (Johnstone, 2008).

'Speech Act' which is a "functional unit in communication" (Cohen, 1996, p. 384; Richards \& Schmidt, 2002, p. 498), consists of actions such as requesting, apologizing, commanding etc. (Yule, 1996). Speech act theory, brought forth by the philosopher John Austin (1962) and later developed by John Searle (1969), "analyses the role of utterances in relation to the behavior of the speaker and hearer in interpersonal communication" (Crystal, 2003, p. 427). There are various speech acts with which learners need to be familiarized such as gratitude, apology, request etc.

One of the speech acts which requires to be investigated and has been left somehow untouched is 'the speech act of correction'. Therefore, in this study we are about to explore how Iranian EFL learners perform self-correction if they make a mistake, and whether they differ in their speech acts or their preferences if their age, gender, proficiency level or culture change.

\section{THEORETICAL FRAMEWORK}

Correction is called for in any ELT class since learners consider correction as a source of improvement (Chaudron, 1988, as cited in Celce-Murcia, 2001), but it is the teacher who determines the most proper time for correction, the best type of that and whether to correct or not. There are different types of correction (Brown, 2007; Celce-Murcia, 2001): Explicit/ Direct (Brown, 2007), Implicit/ Indirect (Richards \& Schmidt, 2002), Peer-correction (Paulston \& Bruder, 1976), Self-correction (Swain, 1985), Clarification request, Repetition, Recast, Metalinguistic feedback, Elicitation (Brown, 2007).

According to Brown (2007, p. 379), corrective feedback includes responses to learners' produced utterances which "repair" or "call attention" to their errors. When a mistake is made in ELT classrooms, it might be corrected by the teacher, the learner or others. Overall, the situations where learners make the correction are as follows: 
Teacher makes a mistake (teacher-correction)

Peers make a mistake (peer-correction)

They themselves make a mistake (self-correction)

In the current study, we are dealing with the third type, and therefore it will be discussed in detail. Self-correction as defined by Sultana (2009, p. 11), is "the technique which engages students to correct their own errors". In other words, self-correction happens when "the speaker hears himself/ herself make a mistake in pronunciation, grammar, choice of words etc. and immediately corrects it" (Lam, 2006, p. 144).

A concept which is closely connected with self-correction is 'learner autonomy', i.e. when learners are encouraged to correct their own mistakes, not only they become independent, but also as Makino (1993, p. 340) puts it, they are given "an opportunity to consider and activate their linguistic competence, so that they can be active participants". Therefore, as many scholars have already suggested (e.g. Makino, 1993, Rief, 1990), teacher correction might be very helpful to some learners, but self-correction might be more beneficial to others and must be encouraged.

Havranek and Cesnik (2001) believe that when learners can perform self-correction, it means that they know the correct form or may have it as an alternative in mind. "What is missing is fine-tuning, confirmation of the correct alternative, and routine access to it", which is achieved through self-correction" (p. 107). So what teachers are required to do is to 'involve' learners, and therefore foster learning.

"A student's utterance that immediately follows the teacher's feedback and that constitutes a reaction in some way to the teacher's intention to draw attention to some aspect of the student's initial utterance" is called 'uptake' (Lyster \& Ranta, 1997, p.49). Therefore, when a learner produces an erroneous utterance, it may be followed by teacher's feedback resulting in teacher-initiated correction which is uptake, or the error might be noticed and corrected by the learner himself/ herself which might lead to a self-initiated correction.

In recent learner-centered educational settings where collaborative learning is exercised and learner autonomy is highlighted, 'self-correction' is required and has been proved essential (Edwards, 2000; Rief, 1990; Sultana, 2009). However, as Sultana (2009) also suggests, the specific educational context and learners' demands must be examined carefully before the application of any method or technique.

Hitherto, plenty of research has been carried out on speech acts in English including various cross-cultural studies which have compared and contrasted English speech acts with those of other languages such as Persian, Chinese, Japanese, Spanish, and Turkish. Speech acts such as compliment (e.g. Grossi 2009, Tang \& Zhang 2008), refusal (e.g. Chang 2008, Ken, Lin \& Tseng 2006), request (e.g. Kilıçkaya 2010, Jalilifar 2009), apology (e.g. Shariati \& Chamani 2009, Afghari 2007), complaint (e.g. Young 2008, Umar 2006), and disagreement (e.g. Guodong \& Jing 2005) have been dealt with so far.

As it is obvious, one of the noteworthy speech acts which has not captured researchers' interest is the speech act of correction, though it is quite significant in teaching. There are merely a few studies available in this realm such as those of Takahashi and Beebe (1993) and Pishghadam and Kermanshahi (in press).

The issue of 'correction' has also been dealt with a lot so far. Among copious research on correction, we can refer to that of Panova and Lyster (2002) who observed patterns of error treatment in ESL classrooms and tried to find a relationship between feedback type and learners' response. Many researchers highlighted the type of correction favored by teachers and learners and concluded that teachers prefer indirect correction (Ellis, Basturkmen, \& Loewen, 2001). Some other researchers such as Vickers and Ene (2006) examined correction in writing who concluded that the most effective type is self-correction since it leads to greater grammatical accuracy. Still other scholars studied peer correction in writing and ESP courses or investigated its effectiveness (Edwards, 2000; Rollinson, 2005; Hansen \& Liu, 2005).

What matters most in all mentioned situations is the speech act through which correction is made. However, unfortunately, few studies have analyzed the speech act of correction in depth so far and have focused on learner correction as well- Takahashi and Beebe (1993) and Pishghadam and Kermanshahi (in press). In these studies only two aspects of learner correction have been investigated and those are learners correcting teachers and learners correcting peers, not the aspect under study in the current research_learners correcting themselves.

\section{PURPOSE OF THE STUDY}

As mentioned earlier, it seems that a great deal of research has been carried out in other realms of speech acts including refusals, requests, apologies, compliments, complaints etc. However, the speech act of correction had remained somehow untouched. Moreover, there are plenty of studies (e.g. Havranek \& Cesnik, 2001; Rief, 1990; Schegloff, Jefferson, \& Sacks, 1977; Sultana, 2009) which studied the issue of self-correction, all focusing on the distinction between self and other-correction, advantages and disadvantages of giving feedback by the teacher or learners themselves, the relationship between learner characteristics and the effectiveness of corrective feedback. However, none of these researchers highlighted the speech act through which a learner corrects himself/ herself. Therefore, paucity of research in this realm makes this particular study significant, with the chief purpose of delving into ELT classrooms to discern how EFL learners self-correct, whether the speech act of correction differs among different age groups, whether males and females apply the same speech acts for correction and how culture influences the way learners give feedback. 


\section{METHODOLOGY}

\section{A. Setting and Participants}

This research was carried out in language institutes in Mashhad, a city in Iran, and a community sample of 160 EFL learners participated, comprising 80 males and 80 females aged between 15 and 45. In this study, age, gender, proficiency level are the three variables whose roles were to be examined. First, to determine the role of proficiency level in the speech act of correction, the sample comprises EFL learners of three different levels- starter $(\mathrm{N}=50)$, intermediate $(\mathrm{N}=50)$, and advanced $(\mathrm{N}=50)$. Second, the present study seeks to figure out whether age plays any crucial role in the corrective behavior or not; so among the participants 80 are adults and 80 are teenagers. Third, the effect of gender on the use of speech act of correction was a salient point to be investigated in this research.

\section{B. Instrumentation}

Among various methods of data collection on speech acts, the most straightforward one which will gather a lot of data at full pelt is through discourse completion questionnaires (Cohen, 1996).

For collecting data, a questionnaire was designed based on the guidelines provided by Takahashi and Beebe (1993), Pishghadam and Kermanshahi (in press), and personal teaching experiences. There is a situation where a mistake is made by the learner himself/ herself and the participants must pen how they would react to their own mistake. Four options were provided to aid the participants, and a space to write their opinion if it was not included, as it follows:

\section{Situation}

You are a student in an English class. You make an example and at the end you realize you made a mistake; instead of 'they had gone' you have said 'they have gone'.

A) I would probably say nothing.

B) 'Oh, no excuse me... They had gone'.

C) I'd ask my friend 'was it correct'?

D) I'd wait for the teacher to correct and then I'd say 'yes'.

$\square$ Something else:

The content validity of this questionnaire was substantiated through a pilot study in which 60 EFL learners took part. On the recommendations of an expert in this field and based on the feedback received from participants, questions were revised and ambiguities were removed.

\section{Procedure}

In October (2010), at the beginning of a new semester in language institutes, the process of data collection started and it ended in December (2010) after 3 months. The designed questionnaires were distributed among EFL learners in different language institutes. Their classes were interrupted for 10 minutes by kind permission of their teachers; some instructions and needed guidance were provided by the researchers before responding. Then, the participants had about 3 minutes to read the situation and options and to decide on their responses. The questionnaires were collected afterwards to be analyzed.

The options selected by the respondents were transformed into tables displaying the frequency and percentage of each, and three tables were compiled, each focusing on one of the variables under study. Then, the tables were analyzed qualitatively through comparing and contrasting the options. The participants of each group - males and females, adults and teenagers, starter, intermediate and advanced learners - were compared and the results were discussed.

\section{RESULTS}

In the designed questionnaire, learners are asked to mention how they would react if they make a mistake in answering a question, and there are four options to be checked off in this situation. Based on the collected data, the influence of the three different variables are to be examined (gender, age and proficiency level). For the first part of the analysis, we are to demonstrate whether females' and males' self-correction differs, and if it does what the differences are, i.e. what the role of gender in self-correction is.

TABLE I.

FREQUENCY AND PERCENTAge OF ANSWERS TO EACH OPTION CONSIDERING GENDER

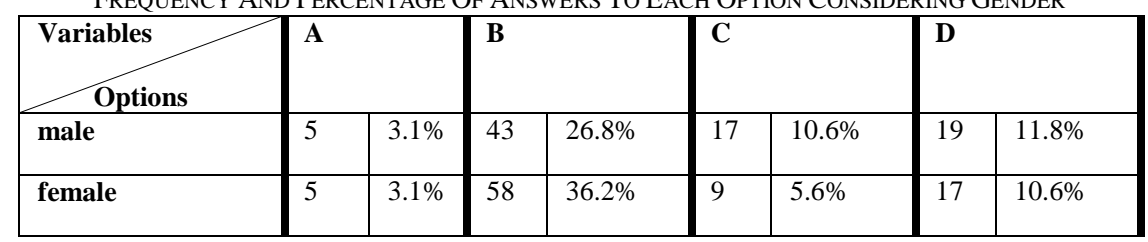

According to Table 1, males and females do not differ in the priority they have given to the options. Both groups selected option 'B' more than any other option (36.2\% of females and $26.8 \%$ of males):

Oh, no excuse me... 'They had gone'. 
This indicates that no matter what the gender is, learners try to self-correct when realizing a mistake in their utterance. And they might add exclamations such as "oh, no!" or "excuse me" to show they have realized the mistake.

The second option selected by most male and female learners is option ' $\mathrm{D}$ '. $11.8 \%$ of males and $10.6 \%$ of females opted for this option in the second place:

I'd wait for the teacher to correct and then I'd say 'yes'.

It can be inferred that Iranian EFL learners try to correct themselves in the first place, if not, they would rely on the teacher to do that and they would merely confirm. Less number of them rely on peers for correction (option C), and very few of them tend not to correct at all. The summary of the results obtained for the first part are displayed below:

\begin{tabular}{|l|l|}
\hline males & $\mathrm{B}>\mathrm{D}>\mathrm{C}>\mathrm{A}$ \\
\hline females & $\mathrm{B}>\mathrm{D}>\mathrm{C}>\mathrm{A}$ \\
\hline
\end{tabular}

TABLE II.

FREQUENCY AND PERCENTAGE OF ANSWERS TO EACH OPTION CONSIDERING AGE

\begin{tabular}{|l|l|l|l|l|l|l|l|l|}
\hline \begin{tabular}{|l|l|l|l|} 
Variables \\
\multicolumn{1}{|l|}{ Options }
\end{tabular} & \multicolumn{2}{l|}{ B } & \multicolumn{2}{l|}{ D } \\
\hline adult & 4 & $2.5 \%$ & 53 & $33.1 \%$ & 13 & $8.1 \%$ & 14 & $8.75 \%$ \\
\hline teenager & 4 & $2.5 \%$ & 49 & $30.6 \%$ & 13 & $8.1 \%$ & 21 & $13.1 \%$ \\
\hline
\end{tabular}

The obtained results for part two -the influence of age on self-correction- seem to be exactly the same as that of the previous part with minute differences in percentage of each. Both adults and teenagers opted for option 'B' more than the other ones ( $33.1 \%$ of males and $30.6 \%$ of females). The second favored option by both groups is again option ' $\mathrm{D}$ ', the third one ' $C$ ' and the last one ' $A$ '.

Up to this point we can deduce that neither Iranian male and female EFL learners differ in the way they self-correct, nor adults and teenagers, i.e. gender and age do not play any significant role in the process of self-correction by Iranian EFL learners. Moreover, it is inferred that they mostly tend to correct themselves at the first onset, and will rely on the teacher in the second place or their peers at the end. The summary of results about the effect of age is displayed below:

\begin{tabular}{|l|l|}
\hline Adults & $\mathrm{B}>\mathrm{D}>\mathrm{C}>\mathrm{A}$ \\
\hline Teenagers & $\mathrm{B}>\mathrm{D}>\mathrm{C}>\mathrm{A}$ \\
\hline
\end{tabular}

TABLE III.

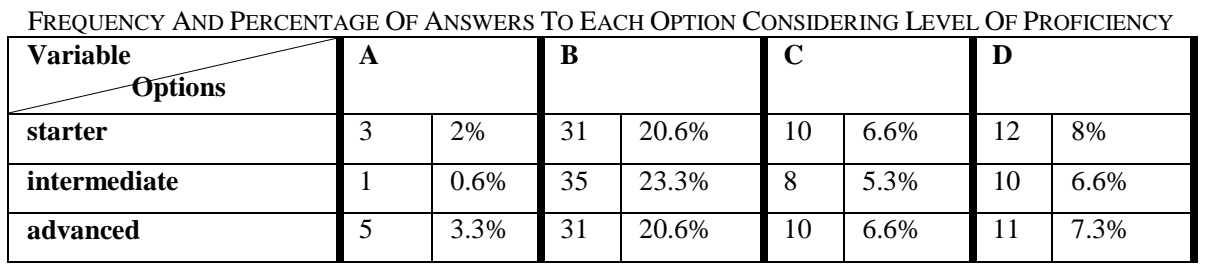

According to Table 3, most starters (20.6\%), intermediate learners (23.3\%) and advanced students (20.6\%) selected option ' $\mathrm{B}$ ' (self-correction) as the most favored one. The next selected options are ' $\mathrm{D}$ ' (reliance on teacher), ' $\mathrm{C}$ ' (reliance on peers) and ' $\mathrm{A}$ ' (no correction) in sequence. Therefore, it is inferred that Iranian EFL learners at any proficiency level, seem to correct themselves when noticing a mistake, that is even if they are starters, they first rely on themselves and then on the teacher or classmates. The results of the role of proficiency level in self-correction are summarized below:

\begin{tabular}{|l|l|}
\hline Starter & $\mathrm{B}>\mathrm{D}>\mathrm{C}>\mathrm{A}$ \\
\hline Intermediate & $\mathrm{B}>\mathrm{D}>\mathrm{C}>\mathrm{A}$ \\
\hline Advanced & $\mathrm{B}>\mathrm{D}>\mathrm{C}>\mathrm{A}$ \\
\hline
\end{tabular}

Overall, based on the results of the current study, age, gender and proficiency level do not play any major role in Iranian EFL learners' self-correction, that is no matter what the age, gender and proficiency level are, most of them prefer to correct themselves if they make a mistake.

\section{DISCUSSION}

According to the presented findings in the previous section, Iranian EFL learners tend to self-correct when they notice a mistake in their utterance, independent from their age, gender or level of proficiency. This might be closely connected to the idea of 'learner autonomy'. They try to be independent from the teacher or peers when repairing. 
A salient point to be discussed is the distinction between 'self-correction' and 'other-correction'. The participants of the current study seemed to be more interested in the first one rather than the latter. As Schegloff, et al. (1977, p. 361) define them, self-correction is done "by the speaker of that which is being corrected" and other-correction is "correction by some 'other' ". In the current setting, the others are the teacher and peers; therefore, it may be due to the growth of the idea of 'learner autonomy' in educational context of Iran, or some innate characteristics of Iranian learners such as 'self-reliance', that they mostly prefer to rely on themselves rather than the 'others'.

The role of culture and environment can also be highlighted here. Iranian EFL learners seemed to be interested in self-correction and self-reliance, so this is open to more research to examine whether it is the same in other cultures, whether other EFL learners prefer self-correction to teacher correction and peer correction if they notice a mistake in their utterance or not. And how they would correct themselves would be of great importance, i.e. the question arises whether or not they would apply similar speech act of correction.

The process of self-correction is closely connected to another issue, i.e. the initiation of the correction. Sometimes it is self-initiated and sometimes 'other-initiated'. If the learner makes a mistake, the teacher repeats or highlights the erroneous part in some way, and the learner self-corrects, it would be teacher-initiated. However, as Havranek and Cesnik (2001) indicate, "when the learner is able to self-correct he probably already has at least partial knowledge of the correct structure or is considering it as an alternative", so sometimes the correction is self-initiated. In the proposed situation of the current study, the latter type is suggested, i.e. the learners themselves notice there is a mistake, and therefore the results are confined to that.

As it has been previously mentioned, regarding the interlocutors in an ELT classroom, there are three types of correction for a mistake by learners: teacher correction, peer correction and self-correction. Though the first two types have been proved helpful (Pishghadam \& Kermanshahi, in press), there are also some disadvantages with them. When the teacher corrects learners, his/ her authoritative role is reinforced and that is in contrast with cooperative learning, and when peers correct their friends it may lead to "open conflict" between them as they are "all highly competitive in nature" (Edwards, 2000, p. 294).

No method of correction by itself has been proved effective, and self-correction is not an exception. However, there are some positive points about it which motivates teachers in its application. When learners are involved in something they will learn it better than the time they are passive, and as Havranek and Cesnik (2001, p. 107) put it, in the process of self-correction the learner is "actively involved and must make an effort in order to correct himself", and therefore it will lead to learning. Benjamin Franklin's quotation can well summarize the mentioned points: "Tell me and I forget. Teach me and I remember. Involve me and I learn."

Examining the results of this study, several implications are put forward; first, it will bring about consciousnessraising of those involved in EFL/ ESL learning or teaching through informing them about self-correction and learners' tendencies in different ages, levels or gender. Second, this study will be of great importance to cross-cultural studies which aim to compare different cultures and figure out the sources of cross-cultural miscommunication or failure. Though the subject of self-correction has been previously discussed, the speech act through which learners correct themselves, and how age, gender and proficiency level influence this speech act proposes a lot more to write about.

As it was mentioned before, when learners make a mistake, the three types of correction involved are: teacher correction, peer correction and self-correction. In previous studies (Pishghadam \& Kermanshahi, in press), the first and second type of correction were examined among Iranian EFL learners and they were compared to other groups, and in the current research, the third type - self correction- was studied. These were all correction situations where learners correct the teacher, their peers or themselves; however, further research is called for to examine the types of correction applied by the teachers as well, i.e. teachers correcting students, colleagues or themselves.

\section{REFERENCES}

[1] Afghari, A. (2007). A sociopragmatic study of apology speech act realization patterns in Persian. Speech Communication 49.3, $177-185$.

[2] Brown, H.D. (2007). Principles of language learning and teaching (5th ed.). White Plains, NY: Pearson Education.

[3] Celce-Murcia, M. (Ed.). (2001). Teaching English as a second or foreign language (3rd ed.). New York: Heinle \& Heinle.

[4] Chang, Y. F. (2008). How to say no: An analysis of cross-cultural difference and pragmatic transfer. Language Sciences 31.4, 477-493.

[5] Chaudron, C. (1988). Second language classrooms: Research on teaching and learning. Cambridge: Cambridge University Press. In Celce-Murcia, M.(Ed.). (2001). Teaching English as a second or foreign Language (3rd ed.). New York: Heinle \& Heinle.

[6] Cohen, A. D. (1996). Speech acts. In McKay, S. L., \& Hornberger, H. N. (Eds.). (1996). Sociolinguistics and language teaching. New York: Cambridge University Press.

[7] Crystal, D. (2003). A dictionary of linguistics and phonetics (5th ed.). Malden, MA: Blackwell Publishing.

[8] Edwards, N. (2000). Language for business: effective needs assessment, syllabus design and materials preparation in a practical ESP case study. English for Specific Purposes 19, 291-296.

[9] Ellis, R., Basturkmen, H., \& Loewen, S. (2001). Preemptive focus on form in the ESL classroom. TESOL Quarterly 35.3, 407432.

[10] Hansen, J. G., \& Liu, J. (2005). Guiding principles for effective peer response. ELT Journal 59.1, 31-38.

[11] Havranek G., \& Cesnik, H. (2001). Factors affecting the success of corrective feedback. EUROSLA Yearbook 1, 99-122. 
[12] Grossi, V. (2009). Teaching pragmatic competence: Compliments and compliment responses in the ESL classroom. Prospect 24.2, 53-62.

[13] Guodong, L., \& Jing, H. (2005). A contrastive study on disagreement strategies for politeness between American English and Mandarin Chinese. Asian EFL Journal 7.1, 1-12.

[14] Jalilifar, A. (2009). Request strategies: cross-sectional study of Iranian EFL learners and Australian native speakers. English Language Teaching 2.1, 46-61.

[15] Johnstone, B. (2008). Discourse analysis (2nd ed.). Malden, MA: Blackwell Publishing.

[16] Ken, C., Lin, S., \& Tseng, Y. (2006). To refuse - the art of saying "no". http://www.shs.edu.tw. (accessed 5/6/2010)

[17] Kilıçkaya, F. (2010). The pragmatic knowledge of Turkish EFL students in using certain request strategies. Sosyal Bilimler Dergisi $9.1,185-201$.

[18] Lam, W. Y. K. (2006). Gauging the effects of ESL oral communication strategy teaching: A multi-method approach. Electronic Journal of Foreign Language Teaching 3.2, 142-157.

[19] Lyster, R. \& Ranta, L. (1997). Corrective feedback and learner uptake. Studies in Second Language Acquisition 20, 37-66.

[20] Makino, T. Y. (1993). Learner self-correction in EFL written compositions. ELT Journal 47.4, 337-341.

[21] Panova, I., \& Lyster, R. (2002). Patterns of corrective feedback and uptake in an adult ESL classroom. TESOL Quarterly 36.4, 573-595.

[22] Paulston, C. B., \& Bruder, M. N. (1976). Teaching English as a second language: techniques and procedures. Cambridge, Massachusetts: Winthrop Publishers.

[23] Pishghadam, R., \& Kermanshahi, P. (in press). Speech act of correction: The way Iranian EFL learners correct their teachers. Teaching and Practice in Language Studies.

[24] Richards, J. C., \& Schmidt, R. (2002). Longman dictionary of language teaching and applied linguistics (3rd ed.). London: Pearson Education.

[25] Rief, L. (1990). Finding the value in evaluation: Self-evaluation in a middle school classroom. Educational Leadership 47.6, 24-29.

[26] Rollinson, P. (2005). Using peer feedback in the ESL writing class, ELT Journal 59.1, 23-30.

[27] Schegloff, E. A., Jefferson, G., \& Sacks, H. (1977). The preference for self-correction in the organization of repair in conversation. Language 53, 361-382.

[28] Shariati, M., \& Chamani, F. (2009). Apology Strategies in Persian. Journal of Pragmatics 42.6, 1689-1699.

[29] Sultana, A. (2009). Peer correction in ESL classroom. BRAC University Journal 6.1, 11-19.

[30] Swain, M. (1985). Communicative competence: Some roles of comprehensible input and comprehensible output in its development. In Celce-Murcia, M. (Ed.). (2001). Teaching English as a Second or Foreign Language (3rd ed.). New York: Heinle \& Heinle.

[31] Takahashi, T., \& Beebe, L. M. (1993). Cross linguistic influence in the speech act of correction. In Kasper, G., \& Bulm-Kulka, S. (Eds.). (1996). Interlanguage Pragmatics. Oxford: Oxford University Press.

[32] Tang, C. H. E. N., \& Zang, G. Q. (2008). A contrastive study of compliment responses among Australian English and Mandarin Chinese speakers. Journal of Pragmatics 41.2, 325-345.

[33] Umar, A. M. A. T. (2006). The speech act of complaint as realized by advanced Sudanese learners of English. Journal of Educational \& Social Sciences \& Humanities 18.2, 8-40.

[34] Vickers, C. H., \& Ene, E. (2006). Grammatical accuracy and learner autonomy in advanced writing. ELT Journal 60.2, $109-116$.

[35] Young, K. D. (2008). A Study of complaint strategies for EFL college learners. Modern English Education 9.2, 58-70.

[36] Yule, G. (1996). The study of language (2nd ed.). New York: Cambridge University Press.

Reza Pishghadam is associate professor in Ferdowsi University of Mashhad, Iran. His interests are psychology and sociology of language edcation.

Mohammad Reza Hashemi is associate professor in Ferdowsi University of Mashhad, Iran. His interests are translation and linguistics.

Paria Norouz Kermanshahi is an M.A. student of "English Teaching" in Ferdowsi University of Mashhad, Iran. She got her B.A in "English Literature" in 2007. 